\title{
SPECIFIC CHANGES IN RAPIDLY TRANSPORTED PROTEINS DURING REGENERATION OF THE GOLDFISH OPTIC NERVE ${ }^{1}$
}

\author{
LARRY I. BENOWITZ,* VICTOR E. SHASHOUA, $\ddagger$ AND MYONG G. YOON§ \\ Departments of *Psychiatry and $\ddagger$ Biological Chemistry, Harvard Medical School, McLean Hospital, Belmont, Massachusetts 02178 and \\ $\S$ Department of Psychology, Dalhousie University, Halifax, Nova Scotia, Canada
}

\begin{abstract}
Double labeling methods were used to identify changes in the complement of proteins synthesized in the retinal ganglion cells and transported down the optic nerve during the process of axonal regeneration. Eight to 62 days after goldfish underwent a unilateral optic nerve crush, one eye was labeled with [ $\left.{ }^{3} \mathrm{H}\right]-$, the other with $\left[{ }^{14} \mathrm{C}\right]$ proline. Control and regenerating optic nerves were dissected out and homogenized together after $5 \mathrm{hr}$, a time which allowed us to examine selectively membrane-bound components which migrate in the rapid phase of axoplasmic transport. Proteins from the two sides were co-purified and separated by sodium dodecyl sulfate-polyacrylamide gel electrophoresis. Analysis of the ${ }^{3} \mathrm{H}$ and ${ }^{14} \mathrm{C}$ incorporation patterns along the gels revealed a radical shift away from the normal labeling spectrum during regeneration, with selective changes in labeling at particular molecular weights varying over a 3 -fold range. Eight days after crushing the optic nerve, the greatest increases in labeling were seen for material with apparent molecular weights of 24,000 to $27,000,44,000$, and 210,000 daltons. These peaks declined thereafter, and on days 29 to 39 , the most prominent increases were at 110,000 to 140,000 daltons. These studies indicate a continuously changing pattern in the synthesis and/or degradation of proteins that are rapidly transported down the optic nerve during regeneration and point to molecular species of potential significance in the establishment of the visual map upon the brain.
\end{abstract}

In lower vertebrates, a severed optic nerve will regenerate within a few weeks of being cut, re-establishing the original retinotopic map upon the brain and restoring visually guided behaviors (Sperry, 1945; Jacobson, 1978). Since the first descriptions of this phenomenon in the 1920 's, numerous studies have used optic nerve regeneration as a model system in which to examine the biological events underlying the establishment of highly organized neural networks. Among the changes which occur in the retinal ganglion cells of the goldfish after axotomy are an increase in nucleolar size, a proliferation of free ribosomes, a shift in nuclear position, cellular hypertrophy, and a general increase in protein and RNA synthesis (Murray, 1973; Murray and Forman, 1971; Murray and Grafstein, 1969; Grafstein and Alpert, 1976). Specific protein labeling increases have also been reported for tubulin (Heacock and Agranoff, 1976), actin, and other molecular species in the retina (Giulian et al., 1980). The quantities of protein and RNA transported down the axon increase dramatically, including rapidly transported glycoproteins which become added to the developing nerve terminals (Grafstein and Murray, 1969; Elam and Maxwell, 1978; Feldman et al., 1979; Forman et al., 1971;

\footnotetext{
1 This research was supported by National Institute of Neurological and Communicative Disorders and Stroke Grant NS14674 and by an Alfred P. Sloan Foundation fellowship. We wish to thank Kulu Padda for technical assistance.
}

Ingoglia and Tuliszewski, 1976). Depending upon the temperature, regenerating optic fibers can be seen in the tectum as early as 1 to 2 weeks after an optic nerve crush, with a re-establishment of functional synapses and restoration of behavior occurring a few weeks later (Yoon, 1976; Murray, 1976; Springer and Agranoff, 1977).

In order to identify molecular species which may play a special role in the re-establishment of connections between the eye and the brain, the present study employed double isotope labeling methods to contrast the proteins transported down the regenerating optic nerve with those in the intact contralateral side. Our studies have focused selectively on the group of proteins which moves down the nerve in the rapid phase of axoplasmic transport, since it is these which might be expected to participate in such membrane phenomena as contact guidance, target recognition, and synaptogenesis (Barondes, 1970; Droz et al., 1975; Lorenz and Willard, 1978; Bennett et al., 1973). Our results reveal a continuous shift in the labeling spectrum of rapidly transported proteins during the course of regeneration, with relative changes in the labeling of various molecular species varying over a 3-fold range.

\section{Materials and Methods}

Surgery. Comet variety goldfish (Ozark Fisheries, St. Louis, MO), 4 inches in length, were anesthetized with 
$0.012 \mathrm{M}$ tricaine methanesulfonate (Finquel, Ayerst Laboratories, New York, NY), then placed in a holder with aerated water circulating through the mouth and out the gills. Two parallel incisions were made above the right eye, the bone flap was retracted, and the optic nerve was visualized under a Wild M5A stereomicroscope. The right optic nerve was crushed at two points, 1 and $2 \mathrm{~mm}$ behind the eye, using jewelers' forceps. Gaps in the nerve were verified by gently stretching the glial sheath, which was left intact to insure rapid and reproducible regeneration. After replacing the bone flap, fish were returned to 5gallon tanks containing constantly aerated and filtered water, $20^{\circ} \mathrm{C}$, with $0.1 \% \mathrm{NaCl}$ and $0.01 \%(\mathrm{w} / \mathrm{w}) \mathrm{Na}_{2} \mathrm{~S}_{2} \mathrm{O}_{3}$.

Double labeling. Each goldfish served as a single internally controlled experiment, in which the protein labeling pattern in the regenerating right optic nerve was contrasted with that of the unoperated left side. Equimolar injections of $\left[{ }^{3} \mathrm{H}\right]$ proline (New England Nuclear, NT-285, general label, 1 to $5 \mathrm{Ci} / \mathrm{mmol}$ ) and $\left[{ }^{14} \mathrm{C}\right]$ proline (NC-285, uniform label, $>250 \mathrm{mCi} / \mathrm{mmol}$ ) were used as precursors in the two eyes. Each injection contained 6.7 $\mu \mathrm{g}$ of proline (Pro) in $4 \mu \mathrm{l}$ of phosphate-buffered saline, pH 7.4, injected intraocularly under microscopic guidance with a 10- $\mu$ l Hamilton syringe. An exact basis for comparing the protein labeling patterns of the regenerating and control sides was insured by allowing both sides equal time for synthesis and transport, followed by the co-purification and co-separation of the proteins from the two nerves by gel electrophoresis. In double labeling experiments which compare proteins synthesized in two metabolically equivalent eyes, all molecular species would be expected to have the same ratio of ${ }^{3} \mathrm{H}:{ }^{14} \mathrm{C}$. However, when the two eyes are expressing different protein spectra, molecular species that are being selectively turned on or off can be identified by virtue of their having double isotope ratios significantly different from the mean. In the present experiments, protein synthesis and transport patterns were examined at $8,15,21,29,39$, 49 , and 62 days after crushing the optic nerve, using two or three fish for each time point.

During regeneration, the total amount of label incorporated into the retinal ganglion cells increases severalfold (Grafstein and Murray, 1969; Giulian et al., 1980; Elam and Maxwell, 1978). Since the $\left[{ }^{14} \mathrm{C}\right]$ Pro injections contain only $1 / 20$ of the radioactivity of the $\left[{ }^{3} \mathrm{H}\right]$ Pro injections, the ${ }^{3} \mathrm{H} /{ }^{14} \mathrm{C}$ ratios that are calculated will have a much higher statistical reliability if the ${ }^{14} \mathrm{C}$ is injected in the metabolically active regenerating eye and ${ }^{3} \mathrm{H}$ in the control than if the reverse were done. However, in a number of experiments, we reversed this and injected $\left[{ }^{3} \mathrm{H}\right]$ Pro in the regenerating eye and $\left[{ }^{14} \mathrm{C}\right]$ Pro in the control, in order to verify that measured changes in protein metabolism are not an artifact of how the proteins were labeled.

Labeling time. At $21^{\circ} \mathrm{C}$, rapidly transported proteins move down the goldfish optic nerve at $\sim 40$ to $60 \mathrm{~mm}$ per day (Grafstein et al., 1972). Proteins synthesized in the more peripheral ganglion cells must travel 2 to $3 \mathrm{~mm}$ before reaching the optic disc, and at least $2 \mathrm{hr}$ is required for the first newly labeled proteins from these cells to reach a nerve segment lying $1 \mathrm{~mm}$ beyond the eye (the first $1 \mathrm{~mm}$ is not taken to be certain that we are excluding slower-moving protein species from our analysis). One or two more hours must be allowed so that our assay will include most of the proteins synthesized during the period when appreciable precursor was available in the eyes, and some additional time needs to be added on for the initial period required for newly synthesized peptide chains to undergo post-translational modifications (e.g., glycosylation) and packaging for transport (Goodrum et al., 1979). Empirically, we have verified that somewhere around $5 \mathrm{hr}$ after injection, the amount of labeled protein in the nerve is close to maximal, and we have used this as a standard survival period.

Protein isolation. Animals were sacrificed with an overdose of anesthesia, and under microscopic guidance, the two optic nerves were dissected out from $1 \mathrm{~mm}$ behind the eye up to the optic tectum. The right and left nerves were homogenized together in $5 \mathrm{ml}$ of a modified "brain protein solubilizer" solution (Shashoua, 1976) containing $3 \%$ sodium sarcosinate, $40 \%$ urea, $0.15 \mathrm{~m}$ ethylenediaminetetra-acetate (EDTA), $0.03 \mathrm{M}$ phosphate, $\mathrm{pH}$ 10 , plus nonradioactive proline, $50 \mathrm{mg} / 100 \mathrm{ml}$, to displace noncovalently bound label. The homogenate was heated at $37^{\circ} \mathrm{C}$ for $1 \mathrm{hr}$ to break down aminoacyl-tRNA complexes.

In an attempt to improve the resolution of our analysis, standard subcellular fractionation techniques (Whittaker and Greengard, 1971; Shashoua, 1976) were applied to the optic nerve. Analysis of the various fractions revealed that $80 \%$ of the total radioactivity incorporated into protein came down in the $P_{1}$ fraction (nuclei and debris); the $P_{2}$ fraction (crude synaptosomal), which had most of the remainder of the label, had a specific activity that was no higher than that of $P_{1}$. Thus, no advantage was seen from fractionating the tissue, and the whole optic nerve homogenate was used thereafter to obtain high enough levels of radioactivity for analysis.

Samples were dialyzed against 0.01 to $0.03 \mathrm{M}$ phosphate buffer, $\mathrm{pH} 7.4$, containing nonradioactive proline (three changes, 8 to $15 \mathrm{hr}$ each at R.T. with stirring). DNase and RNase (10 $\mu \mathrm{g}$ each, both protease free, Sigma Chemical Co.) were added and the dialysis was continued two more times against water. Samples were then concentrated down to $0.2 \mathrm{ml}$, and $0.1 \mathrm{ml}$ of a solubilizing solution containing $0.03 \mathrm{~m}$ phosphate ( $\mathrm{pH} 6.8$ ), $3 \%$ sodium dodecyl sulfate (SDS), $45 \%$ urea, and $150 \mathrm{~mm}$ EDTA was added. Prior to electrophoresis, samples were heated for $5 \mathrm{~min}$ at $95^{\circ} \mathrm{C}$, after adding $15 \mu \mathrm{l}$ of $\beta$-mercaptoethanol (Kodak) and one drop of bromphenol blue in glycerol.

Electrophoretic separation of proteins. Samples were run on discontinuous 3 to $10 \%$ polyacrylamide-SDS gels (Laemmli, 1970) using a Hoefer slab gel apparatus. The $10 \%$ running gel was $3 \mathrm{~mm}$ thick $\times 80 \mathrm{~mm}$ long with a $3 \%$ stacking gel $15 \mathrm{~mm}$ in length. The total sample (minus 5 to $10 \%$ used for preliminary determination of counts) was loaded into 8-mm-wide wells cast in the stacking gel. A voltage of $50 \mathrm{~V}$ was maintained until the tracking dye was $\sim 5 \mathrm{~mm}$ from the end. Protein standards (Bio-Rad) run in parallel for molecular weight estimation included myosin $(210,000), \beta$-galactosidase $(130,000)$, phosphorylase $b(94,000)$, bovine serum albumin $(68,000)$, ovalbumin $(43,000)$, carbonic anhydrase $(29,000)$, soybean trypsin inhibitor $(21,000)$, and lysozyme $(14,300)$. At the end 
of the run, gels were fixed in $12.5 \%$ trichloroacetic acid (TCA) for $1 \mathrm{hr}$, stained with Coomassie Brilliant Blue (Kodak), and photographed. The "tracks" containing the proteins were cut out and thin copper wires were inserted at the positions of four prominent, readily identified reference bands. Gels were frozen to $-50^{\circ} \mathrm{C}$ and sliced at 1-mm intervals, noting the positions of the reference wires for later use in aligning the different cases. Slices were placed in 20-ml glass vials, dried down, and rehydrated with $100 \mu \mathrm{l}$ of $\mathrm{H}_{2} \mathrm{O}$. Proteins were extracted into the scintillation cocktail (8\% Protosol, 92\% Econofluor, New England Nuclear) by agitating the vials at $37^{\circ} \mathrm{C}$ overnight. Samples then were counted on a Beckman LSC-250 or LSC-255 liquid scintillation counter. Counting efficiency was $\sim 40 \%$ for ${ }^{3} \mathrm{H}$ and $70 \%$ for ${ }^{14} \mathrm{C}$.

Data. Vials were counted for $50 \mathrm{~min}$ or at an error cutoff of $5 \%$ for the ${ }^{11} \mathrm{C}$ channel; most gels were also counted a second time to increase statistical reliability. Corrected ${ }^{3} \mathrm{H}$ and ${ }^{14} \mathrm{C}$ values were obtained by subtracting background values (determined from the actual activity in slices beyond the dye front, usually 10 to $15 \mathrm{cpm}$ ), adjusting for quenching and for spillover of ${ }^{14} \mathrm{C}$ into the ${ }^{3} \mathrm{H}$ channel $\left(\sim 15 \%\right.$; no measurable spillover of ${ }^{3} \mathrm{H}$ into the ${ }^{14} \mathrm{C}$ channel occurs). Counting errors of 5 to $7 \%$ for ${ }^{14} \mathrm{C}$ were accompanied by 2 to $3 \%$ errors for ${ }^{3} \mathrm{H}$, and in the isotope ratios, this translates into errors of $\pm 20 \%(95 \%$ confidence limits). By recounting samples, errors were reduced to $\pm 14 \%$. For each experiment, corrected ${ }^{3} \mathrm{H}$ and ${ }^{14} \mathrm{C}$ activities, along with the isotope ratios, were plotted against gel migration positions. In principle, for an observed change in protein metabolism to be considered statistically reliable, the change in the ${ }^{3} \mathrm{H} /{ }^{14} \mathrm{C}$ ratio would need to exceed $\pm 14 \%$. Gel slices with ${ }^{14} \mathrm{C}$ values between 5 and $10 \mathrm{cpm}$ above background are statistically less reliable (error in ratio, 20 to $30 \%$ ) and were plotted with dotted lines; slices with ${ }^{14} \mathrm{C}$ values less than $5 \mathrm{cpm}$ above background were not plotted at all.

Independence of isotope labeling in the two eyes. Control experiments were carried out to verify that each eye can be studied as a separate channel with little crosscontamination occurring from the precursor injected into the other eye. In six unoperated fish, $\left[{ }^{3} \mathrm{H}\right]$ proline was injected into one eye, $\left[{ }^{14} \mathrm{C}\right]$ proline into the other. Since the optic nerves of the goldfish decussate completely at the chiasma, the ratio of direct:indirect labeling could be determined by measuring the relative amounts of the two isotopes present in the proteins transported to each optic tectum. After an 18-hr survival period, the two tecta were dissected out, together with the cerebellum, the latter tissue being included to measure the extent to which brain tissue that does not receive retinal input becomes labeled systemically. Each tissue was homogenized separately, the proteins were separated by successive TCA precipitations, and ${ }^{3} \mathrm{H}$ and ${ }^{14} \mathrm{C}$ activity per microgram of protein was determined (Bondy and Madsen, 1971). Radioactivity levels in the tecta were corrected for systemic labeling (using the data from the cerebellum), and the ratio of the remaining ${ }^{3} \mathrm{H}$ and ${ }^{14} \mathrm{C}$ was normalized by the ratio of the two isotopes in the cerebellum (to standardize for the initial precursor pool ratio). This then gave a value of the specific:nonspecific labeling for the transported proteins.
Isotope artifacts. To be able to make double labeling comparisons, it was necessary to demonstrate that $\left[{ }^{3} \mathrm{H}\right]$ and $\left[{ }^{14} \mathrm{C}\right]$ proline are not metabolized differentially. Five hours after labeling the right and left eyes of an unoperated fish with the two isotopes, the optic nerves were dissected out and homogenized together, and their proteins were co-purified and separated by gel electrophoresis. Since the two eyes are in metabolically equivalent states, all molecular species would be expected to have the same ratio of ${ }^{3} \mathrm{H} /{ }^{14} \mathrm{C}$ if there were no preferential incorporation of either isotope into proteins or differential catabolism of the precursors. Isotope artifacts would be apparent from nonlinearities in the ${ }^{3} \mathrm{H} /{ }^{14} \mathrm{C}$ ratio. Further evidence against isotope artifacts was obtained in other experiments which contrasted the double labeling ratio profiles in cases in which ${ }^{3} \mathrm{H}$ was injected in the regenerating eye, ${ }^{14} \mathrm{C}$ in the control, and cases where the isotopes were reversed.

\section{Results}

\section{Protein labeling profile in the intact optic nerve}

The staining pattern of optic nerve proteins separated on $10 \%$ polyacrylamide-SDS gels is shown in Figure $1 A$. This profile reflects the relative abundance of all protein constituents of the optic nerve and would be expected to be dominated by the principal components of the axonal matrix (e.g., tubulin, neurofilament proteins) and of the Schwann cells. The rapid phase of axoplasmic transport contributes only a very small fraction of the total protein complement present in the nerve at any one time, and as shown in Figure $1 B$, its isotope incorporation profile is strikingly diffurent from the composition of the nerve as a whole. In contrast to the staining pattern, where the most prominent bands lie at the center of the gel and beyond, the intra-axonal proteins, which are most heavily labeled $5 \mathrm{hr}$ after intraocular $\left[{ }^{3} \mathrm{H}\right]$ proline injections, appear in the upper third of the gel (molecular weight > 100,000 daltons). Both the labeling and staining profiles show accumulations of fast-migrating material at the dye front.

\section{Changes in the rapidly transported proteins on day 8 of regeneration}

Figure $2 A$ contrasts the isotope incorporation profiles of rapidly transported proteins for an optic nerve that has been regenerating for 8 days and for the intact contralateral side. Both labeling profiles have been normalized to express the radioactivity per slice as a fraction of the total labeling in the gels. A number of striking differences are apparent between the two sides: The regenerating nerve contains greatly increased amounts of proteins having apparent molecular weights of 210,000 and 44,000 and lesser increases at 155,000, 76,000, 54,000, and before the dye front $(27,000)$. Relative decreases on the regenerating side are seen for material migrating with apparent molecular weights of 113,000 to $140,000,58,000$, $50,000,36,000,29,000$ to 33,000 , and at the front.

The ratio of isotope labeling on the regenerating side to that in the control is plotted in Figure $2 B$. With the data represented in this manner, the relative labeling changes for various protein species are seen to vary over 
(A) GEL STAINING PROFILE: WHOLE OPTIC NERVE

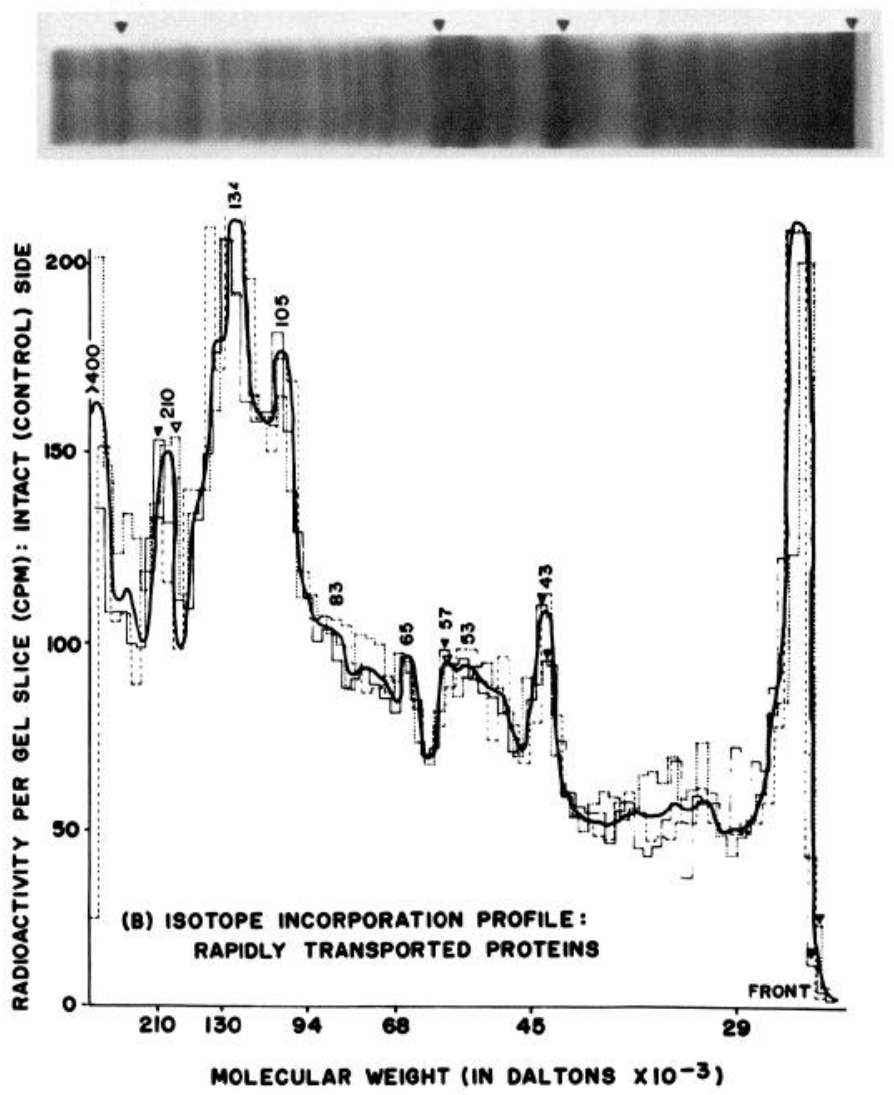

Figure 1. A, Total protein complement of the goldfish optic nerve. Proteins were separated on a discontinuous 3 to $10 \%$ polyacrylamide-SDS gel (Laemmli, 1970) and stained with Coomassie Brilliant Blue. Small arrows indicate the positions of four reference bands. $B,\left[{ }^{3} \mathrm{H}\right]$ Proline incorporation profile for the proteins in the normal optic nerve $5 \mathrm{hr}$ after intraocular labeling. Profiles from three separate experiments were scaled to the same height and aligned by the positions of the four reference wires, and their average labeling profile was estimated (dark line).

a 2-fold range. A replication of this experiment (Figure $2 C$ ), carried out in another unilaterally operated goldfish on day 8 of regeneration, again shows the most prominent labeling increases on the regenerating side for proteins with apparent molecular weights of $\sim 210,000,44,000$, and 27,000 . Where differences between the two cases do appear, they tend to be quantitative and not qualitative, perhaps attributable to such factors as differences in the states of regeneration for the two animals being compared, frame shifts in cutting the gels, or statistical errors $( \pm 15 \%$ per slice) in the isotope ratios.

\section{Control experiments}

Isotope crossover between the two eyes. Analysis of the labeling in the optic tecta $18 \mathrm{hr}$ after the two eyes were differentially injected with $\left[{ }^{3} \mathrm{H}\right]$ - and $\left[{ }^{14} \mathrm{C}\right]$ proline gave an average value of indirect:direct isotope labeling of $0.033 \pm 0.014$ (range, 0.02 to 0.05 ). This degree of crossover will diminish the resolution of the double labeling comparisons by 4 to $10 \%$, an effect which is clearly not detrimental given the magnitude of the labeling
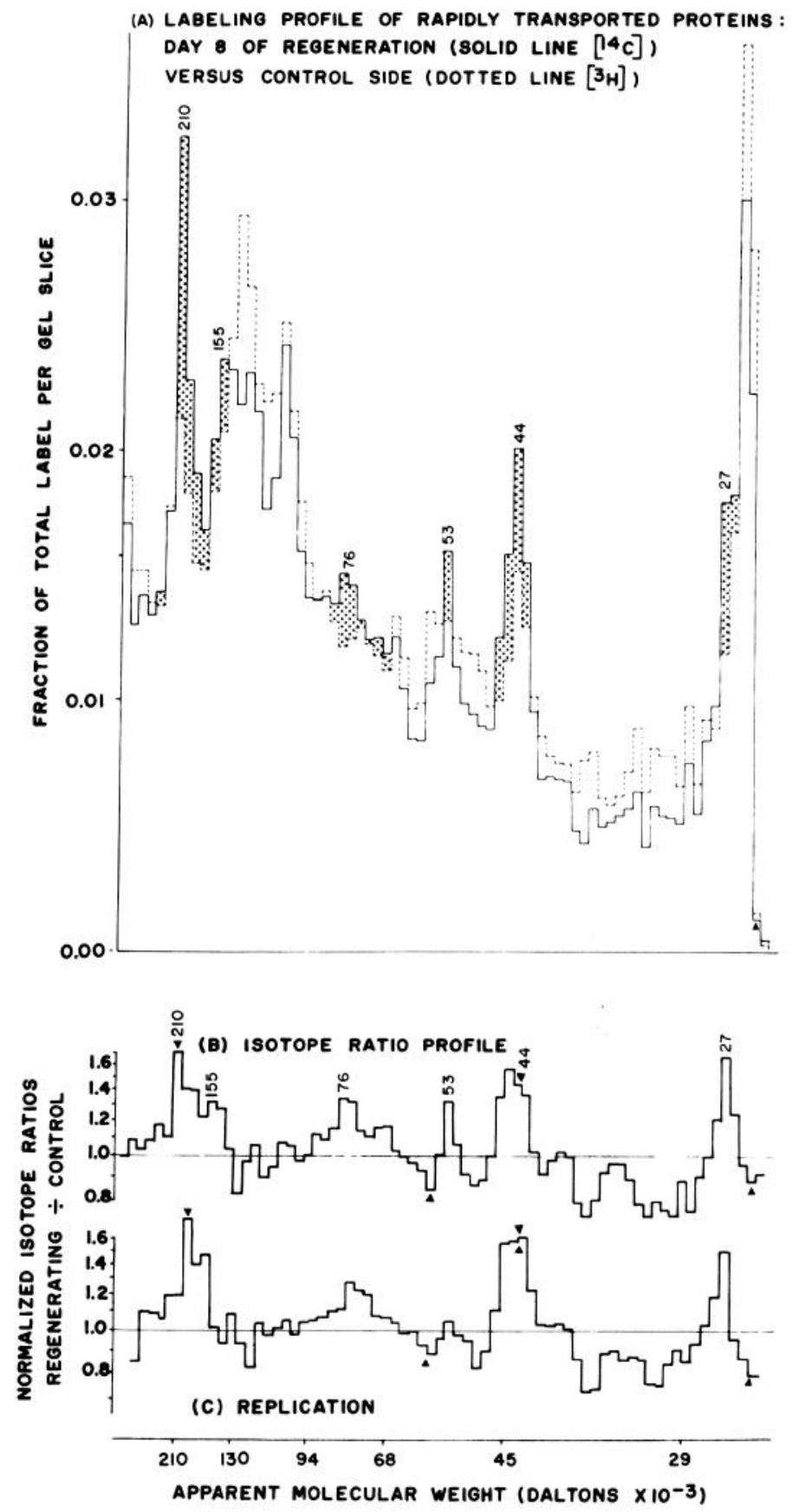

Figure 2. Comparison of rapidly transported proteins on day 8 of regeneration and in the intact state. A: Solid lines, Incorporation profile of $\left[{ }^{14} \mathrm{C}\right]$ proline into proteins on the regenerating side. Dotted lines, Incorporation of $\left[{ }^{3} \mathrm{H}\right]$ proline into the copurified proteins from the control nerve. Data were normalized so that the ordinate gives the radioactivity per $1-\mathrm{mm}$ slice as a fraction of the total label in the gel. Areas where labeling on the regenerating side exceeds that of the control are indicated by shading, and the estimated molecular weights at these points are given. $B$, Ratios of ${ }^{14} \mathrm{C}:{ }^{3} \mathrm{H}$ labeling along the length of the gel. The peaks, indicating regions where labeling in the regenerating nerve most exceeds that of the control, coincide with the shaded areas in $A$. $C$, A similar double labeling comparison done $8 \mathrm{~d}$ after a unilateral optic nerve crush in another fish shows the reproducibility of experimental results from one case to another. 
differences found in these studies. One additional experiment that looked at isotope leakage directly in the optic nerves found no cross-labeling at all.

Evidence against isotope artifacts: Comparison of differentially labeled intact nerves. As shown in Figure 3 , when $\left[{ }^{3} \mathrm{H}\right]$ - and $\left[{ }^{14} \mathrm{C}\right]$ proline were injected into the eyes of an unoperated goldfish, the resulting profile of the double labeling ratio varied by no more than $\pm 10 \%$ around the mean, a variability well within the statistical error $( \pm 14 \%)$ expected for the $95 \%$ confidence limits. These results validate the double isotope methods used in these studies and show that, within a $5-\mathrm{hr}$ survival period, ${ }^{3} \mathrm{H}$ - and ${ }^{14} \mathrm{C}$-labeled molecules are not differentially metabolized in the retinal ganglion cells.

\section{Isotope reversal controls}

More direct evidence that our results do not depend upon the isotopes used comes from studies in which we reversed the labels injected into the regenerating and control eyes. In Figure 4, the solid line shows the double isotope ratio profile for a fish in which $\left[{ }^{3} \mathrm{H}\right]$ Pro was injected into an eye regenerating for $15 \mathrm{~d},\left[{ }^{14} \mathrm{C}\right]$ Pro in the control. The reverse label control, in which $\left[{ }^{14} \mathrm{C}\right]$ Pro was injected on the side which had been regenerating for 15 $\mathrm{d}$ and $\left[{ }^{3} \mathrm{H}\right]$ Pro in the control side, is indicated by the dotted line. In both of these cases, the principal increases in labeling appear for species with apparent molecular weights of $210,000,44,000$ to 45,000 , and before the dye front. These results verify that the results from the double labeling studies are independent of the isotopes used while also demonstrating the replicability of experimental findings for another time point.

\section{Changes in the labeling profile during the regenerative process: Time course studies}

As regeneration proceeds, the labeling profile of the rapidly transported proteins continues to shift. The data shown in Figure 5 represent pooled results from two or three goldfish at seven different time points ranging from 8 to $62 \mathrm{~d}$ after optic nerve surgery. Data from individual fish, shown by the different symbols in the figure, were aligned using the reference wire positions, and the dark lines represent an averaging of individual cases. With increasing times of regeneration, the relative magnitude of all major peaks observed on day 8 diminishes continuously (i.e., proteins having molecular weights of 210,000 , 44,000 , and before the dye front). On day 29 , the greatest

DOUBLE LABELING CONTROL: $\left[{ }^{3} \mathrm{H}\right]$ ANO $\left[{ }^{14} \mathrm{C}\right]$ PROTEINS FROM INTACT NERVES

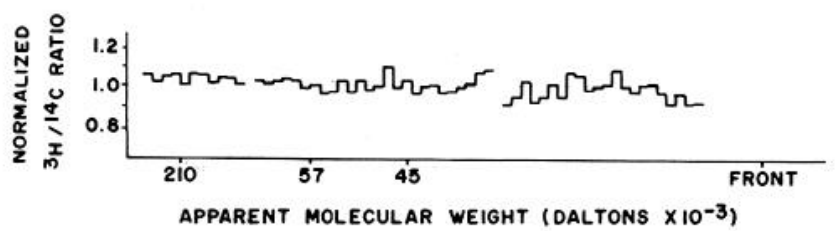

Figure 3. Isotope ratio profile obtained when both ${ }^{3} \mathrm{H}$ - and ${ }^{14} \mathrm{C}$-labeled proteins were derived from intact optic nerves. The absence of fluctuations $\geq \pm 15 \%$ in the ${ }^{3} \mathrm{H} /{ }^{14} \mathrm{C}$ ratio affirms the absence of isotope artifacts in our experimental system.
ISOTOPE REVERSAL CONTROLS: DAY IS OF REGENERATION

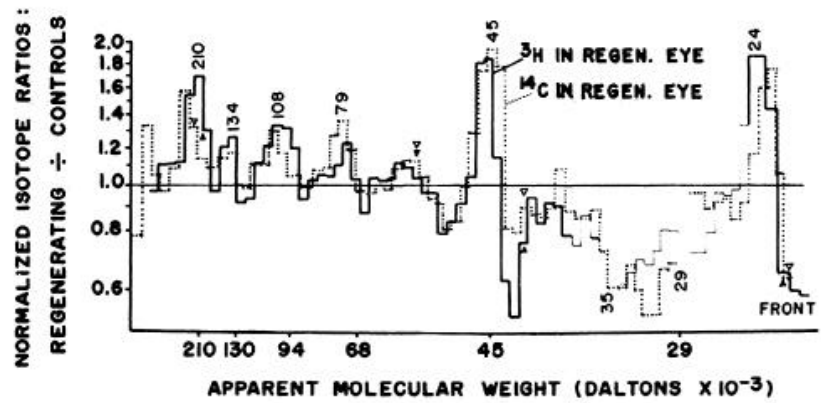

Figure 4. Comparison of proteins transported down the optic nerve on day 15 of regeneration and in the intact state. Solid line, Normalized isotope ratio profile obtained when $\left[{ }^{3} \mathrm{H}\right]$ proline was used as a precursor in the regenerating side, $\left[{ }^{14} \mathrm{C}\right]$ proline in the control. Dotted line, Isotope reversal case, in which $\left[{ }^{14} \mathrm{C}\right]-$ proline was injected in the regenerating side, $\left[{ }^{3} \mathrm{H}\right]$ proline in the control. The similarity between the two profiles indicates that the protein labeling changes observed in the regeneration studies are independent of the isotopes used.

relative increases in labeling appear for proteins with molecular weights of 110,000 to 140,000 ; the relative magnitude of these peaks increases even more so by day 39 before they, too, start to decline. By day 62 , the double labeling profile is returning to linearity, signifying an end to the selective alteration in the labeling of specific rapidly transported proteins with regeneration. In one of the day 62 cases, the double labeling ratio was found to vary by no more than $\pm 15 \%$.

\section{Changes in overall labeling during regeneration}

The present study did not systematically investigate the general increase in total protein transport during regeneration. Nevertheless, some estimate of this effect can be made by comparing the overall isotope incorporation ratio for the two optic nerves when one is regenerating versus when both are in metabolically equivalent states. Such estimates are rather imprecise, however, since the actual precursor pools vary from one animal to another due to differences in the injection sizes and in the leakage of precursors out of the eyes. Given these qualifications, the available material suggests that the total rapidly transported label in the regenerating eye is $\sim 4$ times normal at day 8, 3 times at day 21,2 times at day 29 , and $\sim 1$ time past day 39 , in reasonable agreement with findings from other studies (Grafstein and Murray, 1969; Elam and Maxwell, 1978). For any set of double labeling data, the average isotope ratio should equal the value for the overall labeling increase for that time point (e.g., 4 for day 15, 2 for day 29, etc.). Thus, for example, if a 210,000-dalton protein has a double labeling ratio 1.7 times the median on day 8 of regeneration, the overall increase in labeling relative to the intact state might be estimated as being about 6.8 -fold.

\section{Discussion}

The foregoing results indicate that, in the goldfish, optic nerve regeneration involves a radical shift in the spectrum of proteins which are transported in the rapid phase of axoplasmic flow. While general increases in 


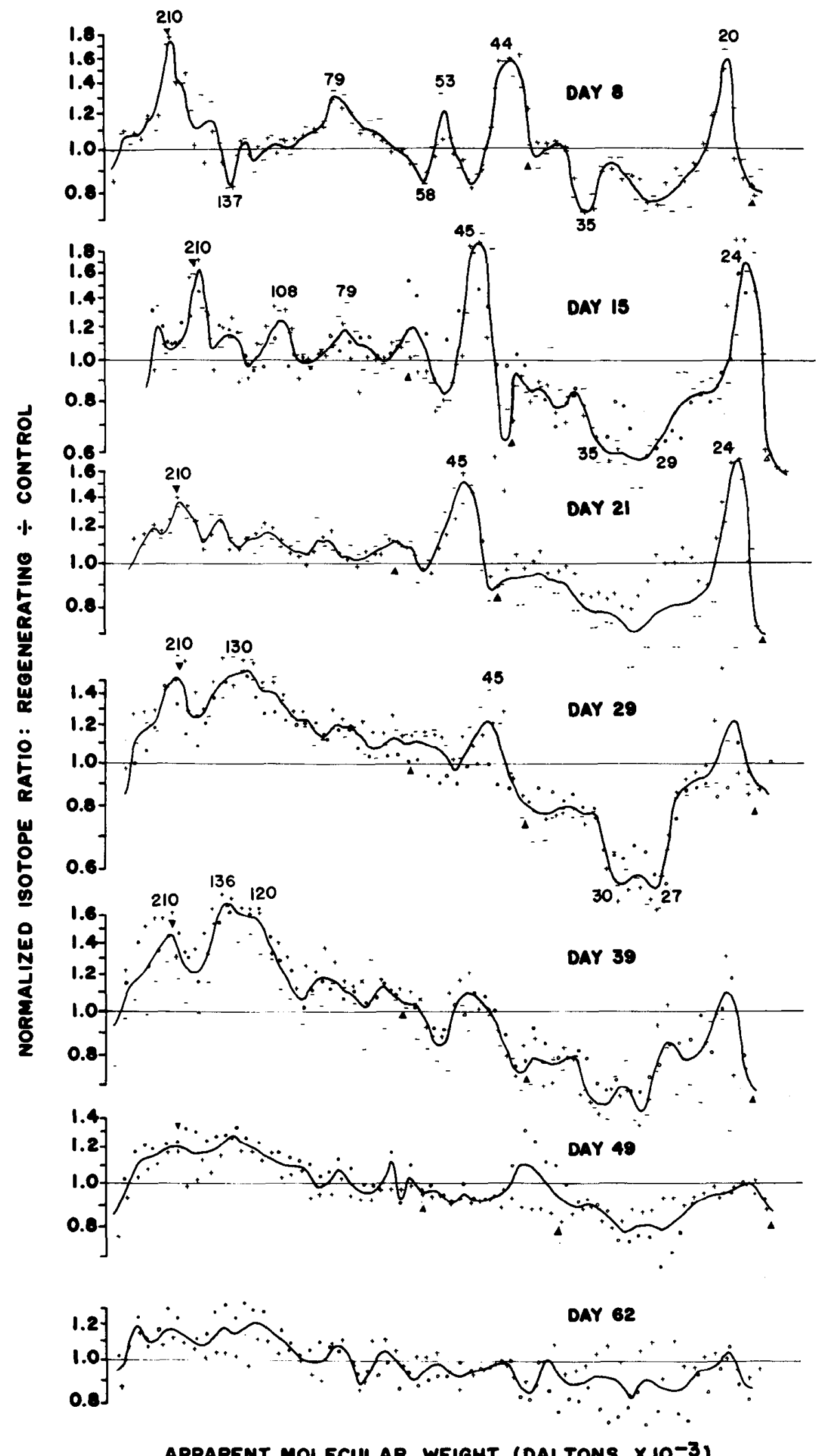

Figure 5. Changes in the complement of rapidly transported protein during the course of optic nerve regeneration. Normalized isotope ratio profiles from individual fish, represented using various symbols $(+,-$, or 0 ), were averaged together at seven different time points. Isotope ratios at the earlier time points vary over a 2 - or 3 -fold range along the length of the gel, indicating a great variability in the extent to which the metabolism of different protein species is selectively altered during regeneration. The qualitative shifts in the profiles for the middle time points suggest a continuously changing program of synthesis and/or degradation of rapidly transported proteins as the regenerative process proceeds. In one day 62 case (shown with +'s), the isotope ratio varies by no more than $\pm 15 \%$ around the median value, indicating a return to the normal metabolic pattern. The $d a r k$ lines represent an averaging of individual cases. 
rapidly transported proteins have been shown previously to occur during regeneration (Grafstein and Murray, 1969; Elam and Maxwell, 1978), the present results show these changes to be selective to particular molecular classes. Eight days after crushing the optic nerve, the greatest relative increases in labeling were seen for material with apparent molecular weights of $\sim 210,000$, 44,000 , and 27,000; decreases appeared at $\sim 130,000$, 58,000 , and between 29,000 and 36,000. With increasing time after surgery, the relative magnitude of these peaks declined and new maxima appeared. On days 29 to 39 , the greatest relative labeling increases were seen for proteins with apparent molecular weights of 110,000 to 140,000 , while minima appeared for material migrating at $\sim 27,000$ to 30,000 daltons. By day 62 , the pattern of protein metabolism and transport in one of our cases had nearly reverted back to normal.

The rapid phase of axonal transport contains membranous material, much of it glycoprotein, which becomes incorporated into the nerve terminals (Lorenz and Willard, 1978; Droz et al., 1975; Bennett et al., 1973). Although this phase of transport includes only a small fraction of the total protein synthesized in the retinal ganglion cells or transported intra-axonally (McEwen and Grafstein, 1968), by selecting an appropriate survival time to examine labeled material in the nerve, we have been able to focus selectively on these proteins while, at the same time, excluding the large amounts of other species involved in such nonspecific processes as construction of the axonal matrix or bioenergetics (Hoffman and Lasek, 1975; Lorenz and Willard, 1978; Brady and Lasek, 1978). From the time course data, we might speculate that the labeling changes in the 110,000 - to 140,000 dalton species seen on days 29 to 39 may reflect events associated with synaptogenesis, while the earlier changes may be correlated more with construction of the growth cone, movement of the filopodia, or perhaps even contact guidance. Clarification of these issues will require extensive research on the structure, function, and anatomical localization of the molecular classes identified here.

While other specific changes in protein metabolism have been associated previously with the regenerating goldfish visual pathway, most would appear to be unrelated to the changes described here. In retinal cells that have been cultured following axotomy, increases in the synthesis of tubulin can be detected during the period in which neurites are being regenerated (Heacock and Agranoff, 1976). An increased synthesis of tubulin, along with actin and other proteins with molecular weights of $\sim 70,000,90,000$, and $\sim 300,000$, have also been reported in studies which use autoradiography to compare the $\left[{ }^{35} \mathrm{~S}\right]$ methionine incorporation profiles of regenerating and control tissues (Giulian et al., 1980). These changes appear both in the retinal ganglion cells and in slow phases of axoplasmic transport $5 \mathrm{~d}$ postlabeling. The absence of a comparable set of changes in the present study is not surprising, however, since we have been examining the rapid phase of transport exclusively. The latter study also demonstrated increases in the $\left[{ }^{3} \mathrm{H}\right] \mathrm{fu}$ cose incorporation, particularly for species with molecular weights $\geq 70,000$, although, since these were detected in the nerve 5 days postlabeling, they too may be slowly transported species.

Another protein change which has been associated with the regenerating retinotectal pathway in goldfish is a 57,000-dalton species whose concentration diminishes in the tectum after cutting the optic nerve and is restored upon regeneration (Quitschke et al., 1979). While this protein may well be transported to the tectum intraaxonally, the absence of a corresponding double labeling change in our studies suggests either $(i)$ that its rate of synthesis and transport is not actually higher during regeneration than in the normal state or (ii) that it does not move down the axon in the rapid phase of transport. Finally, $\alpha$-bungarotoxin binding sites, presumably reflecting nicotinic-cholinergic receptors, have been reported on the developing neurites and in the optic tectum during regeneration of the optic nerve (Schechter et al., 1979; Schwartz et al., 1979), but again, it is difficult to know whether the metabolism of this receptor is actually changing during regeneration or in which phase of axonal transport it might be conveyed.

Methodologically, the present studies demonstrate the feasibility of using double labeling methods to contrast the labeling spectra of proteins synthesized in the two eyes of the same animal. One eye can serve as an internal control for the other, allowing us to rule out the possibility that the observed labeling changes might result from such things as genetic variations between animals, age differences, or differing hormonal modulations of genomic expression. Secondly, the co-purification and coseparation on gels of material from the two sides assures a precise basis for comparing experimental and control protein metabolic patterns. The channel separation in the labeling of the two eyes was found to be 95 to $98 \%$ complete, which means that, in the double labeling comparisons, the actual magnitude of the metabolic changes is underestimated by 4 to $10 \%$. More significant underestimates of the metabolic changes come from the fact that, in using one-dimensional protein separation, the isotope ratios for all species present within a $1-\mathrm{mm}$ slice get averaged together. It might be expected that labeling changes considerably larger than measured here are actually occurring but are being masked by the isotope ratios of other proteins having similar molecular weights. Experiments now in progress which combine double labeling with two-dimensional gel electrophoresis indicate that the labeling changes for some rapidly transported molecular species in the regenerating optic nerve, particularly those having molecular weights of $25,000,44,000$, and 210,000 , are in fact manifold greater than measured here. Other experiments in progress show that most of the labeling changes described here can be demonstrated several hours later in a synaptic membrane-enriched fraction from the tectum, a result which suggests that these proteins are indeed potential candidates for mediating cell-cell interactions important for the formation of the retinotectal pathway.

\section{References}

Barondes, S. H. (1970) Brain glycomacromolecules and interneuronal recognition. In The Neurosciences. Second Study 
Program, G. C. Quarton, T. Melnechuk, and F. O. Schmitt, eds., Rockefeller University Press, New York.

Bennett, G., L. DiGiamberardino, H. L. Koenig, and B. Droz (1973) Axonal migration of protein and glycoprotein to nerve endings. II. Radioautographic analysis of the renewal of glycoproteins in nerve endings of chicken ciliary ganglion after intracerebral injection of $\left[{ }^{3} \mathrm{H}\right]$ fucose and $\left[{ }^{3} \mathrm{H}\right]$ glucosamine. Brain Res. 60: 129-146.

Bondy, S. C., and C. J. Madsen (1971) Development of rapid axonal flow in the chick embryo. J. Neurobiol. 2: 279-286.

Brady, S. T., and R. M. Lasek (1979) Nerve specific enolase and creatine phosphokinase are transported as part of the axoplasmic matrix (slow component b). Soc. Neurosci. Abstr. 5: 58.

Droz, B., A. Rambourg, and H. L. Koenig (1975) The smooth endoplasmic reticulum: Structure and role in the renewal of axonal membrane and synaptic vesicles by fast axonal transport. Brain Res. 93: 1-13.

Elam, J. S., and J. K. Maxwell (1978) Protein and glycoprotein synthesis in degenerating or regenerating optic tract. Trans. Am. Soc. Neurochem. 9: 132.

Feldman, E. L., D. Axelrod, M. Schwartz, and B. W. Agranoff (1979) New neurite membrane is added at the growing tip. Soc. Neurosci. Abstr. 5: 303.

Forman, D. S., B. S. McEwen, and B. Grafstein (1971) Rapid transport of radioactivity in goldfish optic nerve following injections of labeled glucosamine. Brain Res. 28: 119-130.

Giulian, D., H. DesRuisseaux, and D. Cowburn (1980) Biosynthesis and intra-axonal transport of proteins during neuronal regeneration. J. Biol. Chem. 255: 6494-6501.

Goodrum, J. F., A. D. Toews, and P. Morrell (1979) Axonal transport and metabolism of $\left[{ }^{3} \mathrm{H}\right]$ fucose and $\left[{ }^{35} \mathrm{~S}\right]$ sulfate-labeled macromolecules in the rat visual system. Brain Res. 176: 255-272.

Grafstein, B., and R. Alpert (1976) Early changes in the metabolism of goldfish retinal ganglion cells following axotomy. Soc. Neurosci. Abstr. 2: 46.

Grafstein, B., and M. Murray (1969) Transport of protein in goldfish optic nerve during regeneration. Exp. Neurol. 25: 494-508.

Grafstein, B., D. S. Forman, and B. S. McEwen (1972) Fffects of temperature on axonal transport and turnover of protein in the goldfish visual system. Exp. Neurol. 34: 158-170.

Heacock, A. M., and B. W. Agranoff (1976) Enhanced labeling of a retinal protein during regeneration of optic nerve in goldfish. Proc. Natl. Acad. Sci. U. S. A. 73: 828-832.

Hoffman, P. N., and R. J. Lasek (1975) The slow component of axonal transport. J. Cell Biol. 66: 351-366.

Ingoglia, N. A., and R. Tuliszewski (1976) Transfer RNA may be axonally transported during regeneration of goldfish optic nerves. Brain Res. 112: 371-381.

Jacobson, M. (1978) Developmental Neurobiology, Ed. 2, Plenum Publishing Co., New York.

Karlsson, J. O., and J. Sjostrand (1971) Transport of microtubular protein in axons of retinal ganglion cells. J. Neurochem. 18: $975-982$

Laemmli, U. K. (1970) Cleavage of stmuctural proteins during the assembly of the head of bacteriophage T4. Nature 227: $680-685$.

Lorenz, T., and M. Willard (1978) Subcellular fractionation of intra-axonally transported polypeptides in the rabbit visual system. Proc. Natl. Acad. Sci. U. S. A. 75: 505-509.

McEwen, B. S., and B. Grafstein (1968) Fast and slow components in axonal transport of protein. J. Cell Biol. 38: 494-508.

Murray, M. (1973) ${ }^{3} \mathrm{H}$-uridine incorporation by regenerating retinal ganglion cells of goldfish. Exp. Neurol. 39: 489-497.

Murray, M., and D. S. Forman (1971) Fine structural changes in goldfish retinal ganglion cells during axonal regeneration. Brain Res. 32: 287-298.

Murray, M., and B. Grafstein (1969) Changes in the morphology and amino acid incorporation of regenerating goldfish optic neurons. Exp. Neurol. 23: 544-560.

Quitschke, W., A. Francis, and N. Schechter (1979) Analysis of the tectal proteins in the visual pathway of goldfish by $2 \mathrm{D}$ gel electrophoresis. Soc. Neurosci. Abstr. 5: 682.

Schechter, N., A. Francis, D. Deutsch, and M. S. Gazzaniga (1979) Recovery of tectal nicotinic-cholinergic receptor sites during optic nerve regeneration in the goldfish. Brain Res. 166: 57-64.

Schwartz, M., D. Axelrod, E. L. Feldman, and B. W. Agranoff (1979) Histofluorescent identification of $\alpha$-bungarotoxin binding sites in the goldfish visual system. Soc. Neurosci. Abstr. 5: 309 .

Shashoua, V. E. (1976) Brain metabolism and the acquisition of new behaviors. I. Evidence for specific changes in the pattern of protein synthesis. Brain Res. 111: 347-364.

Sperry, R. W. (1945) The problem of central nervous reorganization after nerve regeneration and muscle transposition. $Q$. Rev. Biol. 20: 311-369.

Springer, A. D., and B. W. Agranoff (1977) Effect of temperature on rate of goldfish optic nerve regeneration: A radioautographic and behavioral study. Brain Res. 128: 405-415.

Whittaker, V. P., and P. Greengard (1971) The isolation of synaptosomes from the brain of a teleost fish, Centriopristes striatus. J. Neurochem. 18: 173-176.

Yoon, M. G. (1976) Progress of topographic regulation of the visual projection in the halved optic tectum of adult goldfish. J. Physiol. (Lond.) 257: 621-643. 